\title{
JEAN-FRÉDÉRIC WALDECK Y SUS INVENCIONES DE PALENQUE
}

\author{
Pablo Diener \\ Universidade Federal de Mato Grosso
}

\begin{abstract}
El hábito que tenemos de formarnos una idea sobre los lugares que ya han sido descritos y de los que incluso hemos visto representaciones gráficas, me había inducido a imaginar el sitio de los templos y del palacio de las ruinas llamadas de Palenque; tenía la certeza, con base en los dibujos de Del Río y de Castañeda, que podría circular en esta antigua villa con la misma facilidad con la que lo habrá podido hacer en Egipto [...] el Sr. Denon. A mi llegada a esos lugares, el 12 de mayo de 1832, se desvanecieron aquellas ideas hijas de la imaginación, y en mis expectativas se desmoronó la configuración que yo había construido. ${ }^{1}$
\end{abstract}

Fecha de recepción: $1^{\circ}$ de diciembre de 2016

Fecha de aceptación: 16 de marzo de 2017

${ }^{1}$ NL-Ayer, ms. 1263 , f. 3. Todas las citas de los manuscritos de Waldeck han sido traducidas al español. 
on estas palabras inicia Jean-Frédéric Waldeck (17661875) el esbozo, ya bien estructurado, de su obra sobre el viaje que había realizado a Palenque y a Yucatán, entre mayo de 1832 y enero de 1836. Describe paso a paso su llegada al sitio de Palenque, después de caminar por un sendero escabroso que sube y baja colinas empinadas, franqueadas por restos arquitectónicos ocultos entre los árboles y sus raíces. Por fin, desde lo alto identifica el centro de la antigua ciudad, mientras el murmullo de una caída de agua distrae su atención. Ya en los primeros parágrafos de ese manuscrito, el paisaje es presentado como un factor importante para el reconocimiento y, claro, también para la conservación de las ruinas; su fabulosa exuberancia se transforma en un personaje hostil, con el cual será necesario batallar para alcanzar los objetivos de desvelar el pasado, tarea que el viajero se impone como explorador de las ruinas arqueológicas.

Con desenvoltura descarga vehementes críticas sobre sus antecesores en la tarea de desenterrar los restos de ese universo perdido, autores que lo habían conducido a error, tanto en lo que se refiere a la configuración del espacio, como en cuanto a los detalles del registro de los monumentos.

Narrado en primera persona, Waldeck redacta su descripción con bastante sistematicidad; trata primero sobre los materiales y métodos de construcción y pasa después a describir los monumentos, conduciendo al lector por el intrincado y misterioso laberinto de las ruinas arquitectónicas ocultas por la acción de la naturaleza y el tiempo.

Una y otra vez reitera la impresión que le causa la "acción devoradora de la vegetación, que se encarama por dentro y por fuera” de los edificios, monumentos preciosos que, 
como el Palacio de Palenque, se cuentan entre las más bellas obras del México antiguo. Tanto más le sorprende que poco o nada haya sido hecho para conocer esas ruinas, sea en lo que se refiere a su concepción general, sea en sus detalles. Será precisamente la desidia de los que lo antecedieron en esa exploración lo que le conceda "el placer de descubrir estatuas desconocidas y de hacer, por primera vez, un plan general y particular [de los edificios], siguiendo las reglas del arte". ${ }^{2}$

Pero Waldeck quiere ir más allá de una mera descripción minuciosa, y procura construir una interpretación amplia de los restos arqueológicos de Palenque. Un aspecto sustancial de su propuesta es situar esas ruinas y, de forma general, el conjunto del legado del México prehispánico, en una concepción universal de la historia de la humanidad. Este objetivo no constituye simplemente una preocupación anexa; es el que orienta su mirada de manera persistente. En el curso de la narrativa de viaje, donde da cabida a largas reflexiones históricas, estéticas y filosóficas, en una síntesis afirma: "soy de la opinión que la civilización de lo que se llama nuevo continente es al menos tan antigua como aquellas del viejo mundo, y quizá aún más”. A partir de este principio, busca establecer vínculos transversales entre las diversas culturas de la humanidad mediante las formas visibles de sus obras. Sostiene que, en el legado arqueológico de Palenque, tanto en las formas arquitectónicas como en los ornamentos, en las vestimentas y en la totalidad de las representaciones de las figuras humanas, "se identifican rasgos de los egipcios, los hebreos, los babilonios, los persas,

${ }^{2}$ NL-Ayer, ms. 1263, ff. 4-5. 
los cartagineses, los griegos y los romanos". Con convicción afirma: "Esto ya no es una conjetura. El antiguo y el nuevo continente se han conocido antes de la era cristiana. Eso es positivo. Falta saber cuál fue la nación que abordó a la otra por primera vez". ${ }^{3}$

Estas afirmaciones muestran que Waldeck se había adscrito a la comprensión de un desenvolvimiento unitario de la humanidad y que, con sus exploraciones, quiso proporcionar nuevos datos que dieran fundamento a un entrelazamiento del mundo americano con la historia clásica de Europa y Oriente. Esa interpretación de las culturas americanas, concebida con base en hipotéticos puentes con la antigua tradición cultural del Mediterráneo, Asia Menor y la India, venía ganando terreno desde el siglo xviır. Ya en la segunda mitad del siglo XIX, esas propuestas fueron sistematizadas teóricamente en la vertiente del pensamiento difusionista, primero por el alemán Friedrich Ratzel (18441904), después por el inglés Grafton Elliot Smith (18711937), y aún en la segunda mitad del siglo xx encontraron un cultor entusiasta en la figura del explorador noruego Thor Heyerdahl (1914-2002). El difusionismo incidió, sobre todo, en los estudios de la etnología, la antropología cultural y, también, en la arqueología. Su concepción lleva implícito un culto al genio de los pueblos, lo que condujo a defender la superioridad de unas naciones en detrimento de otras, y derivó en posturas eurocéntricas y racistas de la historia.

En la obra de Waldeck, ciertamente, se constata una connotación valorativa al llevar a la práctica esa construcción intelectual. Él se esmera explícitamente por dejar abierta la

${ }^{3}$ NL-Ayer, ms. 1263, f. 10. 
cuestión de cuál o cuáles serían las culturas primigenias, si bien, de hecho, sus formulaciones suelen tender a dar primacía a la tradición euroasiática.

Podríamos ignorar esas especulaciones, que suelen ser fruto de divagaciones intelectuales bastante aleatorias. No obstante, en la revisión de su legado artístico verificamos que esas ideas tienen una presencia constante. Mirando el mundo desde el continente americano, sus evocaciones del pasado remoto de las culturas del otro lado del Atlántico aparecen reiteradamente en sus escritos. No es casual que entre las primeras frases del esbozo de su obra se compare con el famoso egiptólogo Dominique Vivant, Barón de Denon (1747-1825), que participó como investigador erudito en la expedición napoleónica a la cuenca del Nilo.

Aquí interesa analizar, sobre todo, la injerencia de esa postura de Waldeck en la construcción de su obra artística. Se trata de una producción iconográfica muy vasta y merece un lugar destacado en el conjunto de la obra de los artistas viajeros que visitaron México en el siglo xIx. Entre sus dibujos y pinturas hay vistas del paisaje y estudios costumbristas, pero lo más notable - y también lo más conocido- de su obra es el conjunto de representaciones de tema arqueológico, que abarca desde el valle de Anáhuac hasta Palenque y Yucatán.

$\mathrm{Al}$ revisar sus escritos paralelamente con su obra artística tenemos la impresión de que él ve de acuerdo con las elucubraciones históricas que teje $y$, consecuentemente, registra cada objeto a partir de la lente que modeló a lo largo de los años. Así pues, con independencia de los juicios que fundadamente se han emitido sobre el dudoso valor documental de esos registros, se trata aquí de revisar esa obra 
precisamente en sus invenciones, vale decir, en su contenido artístico y simbólico. Cabe abordar los procedimientos a los que el viajero recurrió en su proceso creativo, observar aquellos aspectos que, desde la perspectiva del saber histórico, han sido rotundamente descalificados, y ponerlos bajo la lupa, interpretándolos como impulsos significativos que condujeron su mano a la hora de construir una configuración visual sui generis del pasado americano.

Al aprender la obra de Waldeck como el legado de un artista viajero, la colocamos en el contexto de una modalidad de producción artística específicamente decimonónica, que pretendió participar de la construcción del conocimiento. Los artistas itinerantes asumían que la intuición les proporcionaba una capacidad de percepción singular, gracias a la cual podían aprehender con exquisita sensibilidad los más insospechados fenómenos naturales y humanos con los que se veían confrontados.

Este artículo se centra en la obra que Waldeck produjo en Palenque porque la difusión de esa etapa de su producción artística ha sido escasa y porque fue ahí donde el pintor modeló su forma de trabajo.

En efecto, este artista viajero publicó poco. La única obra de su autoría que llegó a ver impresa fue su Voyage pittoresque et archéologique dans la province d'Yucatán (Amérique Centrale) pendant les années 1834 et 1836 (París, 1838). ${ }^{4}$ Ese trabajo le valió un modesto reconocimiento de la Sociedad de Geografía de París, en forma de una medalla de bronce, la cual aparece reproducida en el frontispicio del

4 Versión en español: Waldeck, Viaje pintoresco y arqueológico, Mérida, 1930; aquí se usa la edición publicada en México en 1996. 
libro. ${ }^{5}$ De las exploraciones que realizó en Palenque, sólo publicó unos pocos escritos sobre asuntos puntuales y una selección de sus ilustraciones, pero no sus textos, los que aparecieron en 1866 con el título de Monuments Anciennes $d u$ Mexique. Palenque et autres ruines de l'ancienne civilization du Mexique (París, 1866), en una edición realizada bajo los auspicios del Ministerio de Instrucción Pública de Francia, con un estudio de Charles Étienne Brasseur de Bourbourg (1814-1874).

\section{LA SINUOSA CARRERA DE UN AMERICANISTA}

Al tratar de Waldeck nos hallamos, sin duda, ante una figura controvertida. A lo largo de sus 109 años de vida, este personaje fue dejando una estela de incógnitas que se manifiestan en el escabullidizo perfil de su biografía y se materializan de forma contundente tanto en sus escritos como en su obra artística.

No se conoce ningún documento que dé testimonio ni del lugar y fecha de su nacimiento ni de su filiación. En los registros oficiales de Francia se encuentra un certificado del Ministerio de Instrucción Pública, sección de Ciencias y Letras, que le concede por una única vez un beneficio financiero en $1874 .{ }^{6}$ De manera sumaria se informa ahí que habría nacido el 16 de marzo de 1766 y que a los 108 años se encontraba en la miseria más profunda; es identificado

${ }_{5}$ Para la concesión de la medalla véase Walkenaer, Larenaudière y JOMARD, "Rapport sur le concours".

${ }_{6}$ AN, ms. F 17/3238 - Waldeck, Barón de. En el encabezamiento, el documento es identificado como una concesión de "Indemnités Eventuelles". 
como el decano de los viajeros, exalumno del pintor David, que habría viajado por el interior de África con François Levaillant (1753-1824), habría participado en la campaña de Egipto, habría sido compañero de viaje de Robert Surcouf (1773-1827) en la India y, bajo los auspicios de ese ministerio, habría publicado un informe sobre las ruinas de Palenque y de un viaje a Yucatán.

Ese documento simplemente da constancia de aquello que, por muchos años, Waldeck venía construyendo para su biografía. Pero fue sobre todo a partir de la década de 1860 que se empeñó en consolidar públicamente la imagen de sí mismo como un personaje extraordinario, decano de los viajeros y primer pintor de vuelo artístico que visitó y registró las ruinas mayas; ese era un momento de su vida en el cual aspiraba a ocupar un lugar en la Comisión Científica de México, creada por Napoleón III en 1864, y cuando surgió la posibilidad de vender una parte de sus dibujos al Estado francés.

Sabemos, sin embargo, que la mayor parte de las informaciones que el Ministerio de Instrucción Pública asumió como verdaderas al concederle el beneficio financiero de 1874 no es comprobable. ${ }^{7}$ No existe constancia de que viajara por África con el explorador naturalista Levaillant ni de que haya participado en alguna de las numerosas travesías que realizó el navegante y comerciante Surcouf por el océano Índico. Tampoco hay registro de su participación en la campaña napoleónica a Egipto, ni mucho menos de la proximidad que Waldeck afirmaba haber tenido con Bonaparte. La última de las aventuras de la primera mitad

7 Consúltese Cline, “The Apocriphal Early Career”, pp. 278-299. 
de su vida lo habría llevado a Chile en 1819, en compañía del oficial de la marina inglesa, Lord Thomas A. Cochrane (1775-1860). De ahí Waldeck habría emprendido un viaje por cuenta propia a Perú; "partí de Lima" - recuerda en un escrito autobiográfico dirigido al presidente de la Sociedad Americanista de Francia - "siguiendo por el río Marañón que corre hacia el este a través de una infinidad de ríos, uno de los cuales, el Copán, me condujo a las ruinas del mismo nombre"; la intención de esa recapitulación biográfica se desvela unas cuantas líneas más abajo cuando sentencia: "soy, pues, el primer hombre competente que se ha ocupado de las ruinas de América Central y, puedo afirmar, soy el primer americanista". 8

Por medio de la evocación de estas y otras aventuras Waldeck se muestra como un personaje singular, conocedor del mundo y erudito. No se trata de meros desvaríos seniles que haya llevado al papel en los últimos años de su vida. Más allá de errores geográficos de bulto, como el de la ruta que habría seguido de Sudamérica hasta Guatemala, diversos escritos ponen en evidencia que Waldeck se conservó lúcido hasta el final de su vida.

Una amena narrativa biográfica publicada en Filadelfia en 1878 por la estadounidense Mary R. Darby Smith, que visitó a Waldeck en París en 1867 y que relata con entusiasmo y admiración las largas conversaciones que sostuvieron, sugiere, más bien, que él estaba empeñado en concluir la construcción de un personaje que venía forjando a lo largo de medio siglo. ${ }^{9}$ Smith recoge todas sus observaciones e incluso

\footnotetext{
8 WALDECK, "Sur l'archéologie américaine", p. 143.

9 Sмith, Recollections of two Distiguished Persons, pp. 57-97.
} 
se empeña en dar un carácter plausible a una variopinta serie de relatos, sea de la visita que habría hecho a María Antonieta en el segundo día de su prisión en la Conciergerie y del retrato que pintó de ella, sea del encuentro con Lord Byron en Escocia, o también de las frecuentes cenas que habría compartido con Jorge III de Inglaterra.

En aquellos años de finales de la década de 1860, cuando ya había sido publicado el volumen con una selección de sus ilustraciones sobre Palenque, pero sin sus escritos, Waldeck parece decidido a sacar adelante, por cuenta propia, una edición de su obra, que proyectaba financiar mediante suscripciones. En su libro Smith publica el panfleto donde el pintor, que se autodenomina "decano de los viajeros y artistas”, promueve ese proyecto en el que dará a conocer "el resultado de largos años de trabajo" y cuyo objetivo es el de "facilitar los estudios, sobre todo, los estudios comparados de arqueología americana”. Esa es la obra magna de su carrera, que promociona a partir de 1867 y para la que trabajará hasta su muerte, ocurrida el 29 de abril de 1875, sin que haya conseguido llevarla al público. ${ }^{10}$

Después del supuesto paso por Perú y la visita a las ruinas de Copán, episodios biográficos situados hacia 1820-1821 (si bien nunca fueron claramente datados) y que aparecen construidos como el preámbulo inmediato de la carrera de arqueólogo y americanista, Waldeck emerge al horizonte histórico en 1822, en Londres. En ese año están fechados sus trabajos como litógrafo al servicio del editor Henry Berthoud (1790-1864), cuando graba los dibujos de Ricardo Armendáriz para la edición inglesa del informe sobre la

10 Sмiтh, Recollections of two Distiguished Persons, pp. 73-74. 
exploración de Palenque que Antonio del Río (1745-1789) había llevado a cabo en $1787 .{ }^{11}$

En 1825, tres años después de haber ejecutado esa tarea, Waldeck se embarca hacia México, pero no como arqueólogo, sino como ingeniero mecánico, contratado para trabajar en las minas de plata de Tlalpujahua (en Michoacán). A partir de ese momento su vida está documentada con detalle, en primer lugar, por su diario, pero también por medio de los dibujos, acuarelas y pinturas que fue creando a lo largo de la ruta o en los lugares donde se estableció por tiempo más o menos prolongado $\mathrm{y}$, de forma creciente, por testimonios de terceros. ${ }^{12}$

Según registra en su diario, llega a Tampico en el mes de mayo. Su desempeño en la empresa minera fue catastrófico, y ya en febrero de 1826 se libera de lo que califica de "cautiverio de Tlalpujahua" y se establece en la ciudad de México. ${ }^{13}$

A partir de ese momento, cuando estaba por cumplir los 60 años, Waldeck se va revelando más y más como un individuo versátil, con multitud de habilidades y una iniciativa fabulosa. A juzgar por la biblioteca que había llevado

11 Río, Description of the Ruins; véanse las ilustraciones firmadas por Waldeck como grabador.

${ }^{12}$ Los diarios y demás manuscritos de Waldeck pertenecen a los fondos de la BL y de la NL-Ayer. La mayor parte de la obra artística de Waldeck pertenece a los fondos de la BNF-Estampes y a la NL-Ayer; un número menor se encuentra en colecciones privadas. A partir de 1830, el Bulletin de la Société de Géographie, de París, pasa a ser una importante fuente para acompañar los pasos de Waldeck. Para una visión de conjunto sobre los diarios de Waldeck, véase Diener, "El diario del artista viajero", pp. 105-125.

${ }_{13}$ NL-Ayer, ms. 1261 núm. 1, f. preliminar sin número. 
consigo en la travesía a México, poseía un bagaje cultural amplio y una vasta gama de intereses. ${ }^{14}$ Entre los libros que carga figuran la Enciclopedia de Diderot y D'Alembert, un tratado de geografía de Malte-Brun, obras sobre historia natural, mineralogía y anatomía, y también el Diccionario Filosófico de Voltaire. Incluye una serie de libros sobre la Antigüedad clásica, entre otros, un manual de historia antigua, un diccionario griego, la Odisea y obras de Plutarco y Jenofonte. La presencia de nombres como Pierre-Henri de Valenciennes y Charles Percier, con tratados sobre la pintura de paisajes y sobre arquitectura, decorados de teatro y de interiores, respectivamente, así como dos volúmenes sobre monumentos franceses, revela una preocupación por tener a mano herramientas para el quehacer en un amplio espectro de cuestiones relacionadas con el arte.

Vivió en la capital de la República mexicana de febrero de 1826 a marzo de 1832. Fueron años de una incesante y angustiada búsqueda de trabajos que le permitieran no sólo ganar su sustento, sino también que fuesen actividades que calzaran con sus expectativas y que contribuyeran a construir un proyecto de vida a la altura de su horizonte cultural. Pintó retratos, dio clases de dibujo y de pintura, aplicó sus habilidades artísticas en tareas de restaurador, ilustrador o grabador, e incluso se embarcó en la organización de juegos de azar con la esperanza de lucrar. También hizo incursiones en el mundo del espectáculo, una afición que ya aparece registrada en su diario antes de partir de Londres. En la lista de su equipaje figura un chevalet optique, es decir, un caballete óptico cuya función se explica en combinación

${ }^{14}$ NL-Ayer, ms. 1261 núm. 1, f. 2 (anotación del 4 de febrero de 1825). 
con las 2 lampes patente du Major Cochrane, ${ }^{15}$ instrumentos que utilizaría para construir una linterna mágica. Con esto preparó presentaciones de fantasmagoría, a las cuales dedicó horas y días de trabajo pintando las placas de vidrio que serían proyectadas sobre un telón. También se involucró en el montaje de espectáculos de ópera, unas veces como autor de los decorados, otras, incluso, como cantante. Pero ninguna de esas tentativas prosperó como quehacer lucrativo.

En la segunda mitad de 1827 trabó relaciones con Isidoro Icaza, entonces director del Museo Nacional de México. Con entusiasmo registró en su diario que había conseguido un contrato como dibujante y grabador para una publicación de las piezas de la colección del museo. Llegó a dibujar y grabar doce láminas que aparecieron en los tres primeros fascículos de la Colección de Antigüedades Mexicanas que existen en el Museo Nacional y dan a luz Isidoro Icaza e Isidoro Gondra. Litografiadas por Federico Waldeck e impresas por Pedro Robert, publicada en México en 1827. Pero a dos meses de iniciada la edición escribe con enorme frustración: "Estuve con el Sr. Icaza; parece que me veré privado de la obra de antigüedades. No hay dinero para continuar. Qué haré sin esa obra”. ${ }^{16}$

No será sino a partir de 1829 que retomará, ahora por propia iniciativa, actividades relacionadas con el registro visual de México, con énfasis en temas del pasado prehispánico y la arqueología. Desde mediados de ese año aparecen en su diario anotaciones sobre lo que llama “dibujos

15 NL-Ayer, ms. 1261 núm. 1, f. 3 (anotación del 14 de febrero de 1825). 16 NL-Ayer, ms. 1261 núm. 2, f. 212 (anotación del 15 de octubre de 1827). 
de mi colección antigua y moderna de México". ${ }^{17} \mathrm{Al}$ mismo tiempo se hacen más frecuentes sus contactos con viajeros como el comerciante y coleccionista alemán Carl Uhde (1792-1856), el artista viajero Carl Nebel (1802-1855) y, ocasionalmente, el industrial, comerciante y coleccionista suizo Lukas Vischer (1780-1840), personajes que por afición u oficio se interesaban, compraban o registraban visualmente los más diversos objetos del pasado prehispánico. Por fin, en julio conoce personalmente a José Luciano Castañeda (1774-ca. 1834), el ilustrador de la expedición arqueológica de Guillermo Dupaix (ca. 1750-1817), realizada entre 1805 y 1808, y su conversación giró en torno del sitio arqueológico de Palenque; ese encuentro parece haber marcado un momento de inflexión en la vida de Waldeck en México. Con independencia del conocimiento que haya tenido de ese sitio arqueológico a través de la obra de Antonio de Río, el tenor de las observaciones que entonces registró en su diario muestran una aproximación sensible al lugar; retrata un ambiente ameno, donde la gente es buena y los reptiles y las fieras se mantienen a distancia, en las montañas. "Escuché sus comentarios sobre Palenque", - escribe en 17 de julio - "el arroz y el maíz son abundantes [...] un río pasa por medio de las ruinas, y es rico en truchas, y no hay fiebres" ${ }^{18}$ Todo indica, pues, que fue Castañeda quien realmente lo indujo a pensar, por primera vez, en la posibilidad de un viaje a esas ruinas.

NL-Ayer, ms. 1261 núm. 2, f. 335 (anotación del 20 de junio de 1829) y 344 (anotación del 12 de agosto de 1829).

${ }_{18}$ NL-Ayer, ms. 1261 núm. 2, ff. 339-340 (anotación del 17 de julio de 1829). 
Todavía habrían de pasar más de dos años hasta que, por fin, emprendiese el viaje decisivo de su carrera de americanista, primero a Palenque y después a la península de Yucatán. Pero desde que se fijó esa meta, Waldeck orientó su vida a alcanzarla.

Recurrió al gobierno de México con una propuesta para obtener financiamiento por vía de suscripciones para la publicación de "una obra de su viaje, que contendrá doscientas o más láminas, acompañada cada una con su correspondiente texto". Los detalles del proyecto fueron publicados en el Registro Oficial del Gobierno de los Estados Unidos Mexicanos en noviembre de 1831, con el aval de Lucas Alamán, cuando la empresa ya estaba consolidada y con un buen número de adherentes, de los que se mencionan diversos gobiernos de Estado y autoridades eclesiásticas. La obra proyectada es descrita con dimensiones osadas, anunciando que "se sacarán en moldes los bajos relieves de Palenque [...] y se hará de todo una exposición pública en París y Londres, bajo la promesa de que después se entregarán al Museo Nacional”. Y la pluma de Waldeck se trasluce en ese escrito cuando, entre los objetivos, declara que quiere satisfacer "los deseos que los anticuarios de Europa han manifestado de comparar las antigüedades de Palenque con las egipcias". ${ }^{19}$

Su impulso fue apuntalado simultáneamente por la noticia de que, desde 1826, la Sociedad de Geografía de París estaba ofreciendo una medalla de oro de 2400 francos a quien enviase una descripción de Palenque y de la península de Yucatán en texto, imágenes y mapas. En la edición de inicios de 1829

19 Mestre Ghigliazza, “Algo sobre el barón de Waldeck”, pp. 29-30. 
del Bulletin de la Société de Géographie se informaba que la oferta seguía abierta, y en la edición de 1830 se comunicaba una ampliación del plazo para la entrega de los trabajos. ${ }^{20}$ Ansioso por conseguir reconocimiento y siempre atento a la posibilidad de mejorar su situación económica, es muy probable que esta oferta haya contribuido decisivamente para que Waldeck llevara adelante su proyecto.

Revelador de su interés en el concurso abierto por la erudita sociedad parisina y, consecuentemente, de su empeño por acaparar la atención de sus miembros es el hecho de que, por esas fechas, su nombre comienza a figurar con frecuencia en las páginas del Bulletin. Así, por ejemplo, fue probablemente por mediación del propio Waldeck que el cónsul general de Francia en México dirigiera una carta a esa institución informando del proyecto y del auspicio que éste había recibido del gobierno mexicano, y auguraba que muy pronto conseguiría reunir los recursos financieros para poder iniciar el viaje. ${ }^{21} \mathrm{Y}$ al año siguiente las suscripciones lanzadas por el gobierno mexicano son promovidas también en el boletín de la Sociedad de Geografía. ${ }^{22}$

En su diario, Waldeck fue dejando registro de cada uno de los pasos que daba. El tono de sus anotaciones personales es, por lo general, más beligerante que el de sus manifestaciones públicas. Demuestra preocupación de que otro viajero - menciona particularmente a Carl Nebel- se le pudiese

20 Redacción del BULLETIN, “Antiquités Américaines”, pp. 194-196, y Redacción del Bulletin, "Prix pour la Description des Monumens", pp. 186-187.

${ }^{21}$ Cochelet, “Lettre de M. Adrien Cochelet", pp. 101-108.

${ }^{22}$ Véase el anuncio en el Bulletin de la Société de Géographie, 19 (1833), p. 114. 
adelantar en la realización de esta exploración. También se irrita por tener que someterse a la humillación de prolongadas antesalas para conseguir las suscripciones. Y sobre Lucas Alamán, su mentor en el gobierno, descarga diatribas, culpándolo de que la reunión de los fondos no caminase mejor.

Ya con los ojos puestos en su futura expedición, desde la capital hace excursiones a Xochicalco y a Teotihuacán. También reorganiza su biblioteca portátil, desprendiéndose de obras que le traerían algún dinero e incorporando volúmenes que podrían serle útiles en la nueva etapa; entre las nuevas adquisiciones menciona un manuscrito de la obra de Dupaix, cuatro tomos de Antiquities of Mexico de la obra de Lord Kingsborough, la publicación de Antonio del Río y la Historia de la Cindad de Guatemala de Domingo Juarros. Y dedica largas horas a los estudios de historia antigua del Conde de Volnay, a partir de lo que construye asociaciones que vuelan del Joctán del Génesis bíblico a Yucatán y relaciona el mítico país de Ofir - cuya localización era buscada desde los inicios de los tiempos modernos - con algún centro maya. ${ }^{23}$

Por fin, el 5 de marzo de 1832 partió de México en dirección a Veracruz y ahí se embarcó a Tabasco. Poco más de dos meses después, ya en Palenque, envió una nota con tono de entusiasmo a la revista de la Sociedad de Geografía comentando el inicio de sus trabajos:

Hace ocho días que estoy aquí y todavía no consigo restablecerme del estado de admiración y sorpresa. Las ruinas que he venido a estudiar se extienden por el espacio de unas doce a

${ }^{23}$ BL, ms. Add 41684, ff. 21 vo-22 (anotación del 6 de octubre de 1830). 
quince leguas, al borde de una cadena de montañas, por donde corre el río Michol. Son construcciones de todas las dimensiones, que no se parecen en nada a lo que he visto en México. Unas veces aparecen toscamente esbozadas, otras con un bello acabado, y por todas partes, grandes y deslumbrantes. Estoy convencido de que Palenque fue construido por un pueblo de avanzada civilización, en una época que se aproxima a los tiempos heroicos de Grecia [...]. He examinado algunas inscripciones que me han parecido no ser jeroglíficos. ${ }^{24}$

Enseguida el editor comenta con extrañeza la observación sobre las inscripciones: “¿Habrá existido una escritura fonética entre los pueblos de esas antiguas edades, en ese mundo transatlántico, que no es nuevo sino para nuestra presuntuosa ignorancia? Y si esto no es una conjetura vana, ¿a qué sabios de qué raza autóctona acudirán los curiosos europeos en busca de la llave de esas escrituras olvidadas ${ }^{25}$

\section{LA OBRA DE UN ARQUEÓLOGO INUSITADO}

Catorce meses pasó Waldeck en Palenque, de los cuales los últimos cuatro se instaló en el espacio de las propias ruinas. Con el correr del tiempo, en su memoria - en general asumida, sin mayores discusiones -, esa estadía ganó mayores dimensiones, llegando a decirse que había pasado tres años en el lugar.

Para el viajero, Palenque fue el punto culminante de su expedición. Por una parte, ese sitio le permitía crear un puente con su biografía precedente, evocando los grabados

${ }^{24}$ Waldeck y Redacción del Bulletin, “Antiquités Mexicaines”, p. 113. 25 Waldeck y Redacción del Bulletin, “Antiquités Mexicaines”, p. 114. 
de los dibujos de la expedición de Antonio del Río que había realizado en Londres en 1822. Waldeck siempre presentó ese momento como el desencadenante de su afán americanista. La precariedad de esas imágenes habría despertado su curiosidad y, desde entonces, dice haber procurado conocer y mostrar al mundo el verdadero aspecto de aquellos monumentos. Por otra parte, la proverbial fama de ese sitio arqueológico debía contribuir a consolidar su prestigio como desvelador de un pasado recóndito; se trataba de un lugar de más difícil acceso que las ruinas de la península de Yucatán, que recorrió posteriormente, y que a los ojos de sus contemporáneos europeos presentaba numerosas incógnitas que él prometía elucidar. Pero también el hecho de jamás haber podido publicar la obra dedicada a Palenque en la forma que la había concebido desempeñó un importante papel en la mistificación de su propia producción intelectual.

En las anotaciones cotidianas del diario constatamos que Waldeck se muestra empeñado en que su nombre quedara indeleblemente vinculado con Palenque, pasando así a ocupar un lugar entre los grandes descubridores del pasado de la humanidad. Pero el día a día obstaculizaba sus aspiraciones. Describe con majadería los mil y un problemas que entorpecen sus tareas: la mezquindad o la incomprensión de sus contemporáneos, la ineficacia de sus auxiliares cuyo trabajo es lento y torpe, las dificultades para organizar su vida cotidiana, la batalla de vivir con escasos recursos, en fin, la comida, las lluvias torrenciales, la humedad, las termitas y los mosquitos. En la ejecución de sus tareas es de una meticulosidad infinita; dedica días, a veces semanas enteras, a concluir hasta los últimos detalles de un dibujo. Porque, 
de hecho, serían los registros visuales los que darían fe de lo que él - y ¡sólo él! - había visto y comprendido en su verdadera significación.

Los registros que hizo en el lugar son primordialmente visuales. El diario acompaña el trabajo y su existencia cotidiana. Y la mayor parte de las descripciones verbales de los monumentos, así como los comentarios y análisis, por lo general, fueron acrecentados después; esos escritos, a juzgar por las observaciones sobre otras personas y por evocaciones que saltan de un momento a otro del viaje, así como por las características de la letra y de la propia redacción - más clara y mejor construida que el diario-, deben haber sido redactados en Europa, quizá en buena parte cuando retomó su obra ante la expectativa de la venta y publicación de su legado, que se gestionó en París desde finales de la década de 1850.

Al organizar los dibujos palencanos advierte que, en un primer momento, la secuencia era la de un "diario de mi trabajo por jornadas". Posteriormente, al retomar su obra, agrupa las hojas con un criterio temático, de modo que "cada monumento compone una entrega", y en carpetas separadas reúne las imágenes de historia natural y los trajes de los indios, por un lado, y las vistas pintorescas y las costumbres modernas, por otro. Es en la segunda organización de ese acervo que procura adecuar su orden a las necesidades de comprensión de un hipotético público lector al que, finalmente, está destinado. ${ }^{26}$ Entendemos, pues, que como buen artista documentador, el registro regular de su trabajo intelectual, donde fragua su estudio e interpretación de las ruinas, está en los dibujos.

${ }^{26}$ NL-Ayer, Waldeck Drawings, ms. anexo a los dibujos, f. 174. 
En las anotaciones anexas de la lista temática hace un largo preámbulo para construir él mismo una elogiosa evaluación de su obra. Recuerda conversaciones que sostuvo con Frederick Catherwood - el ilustrador inglés de la expedición del explorador estadounidense John Stephens, viajeros que estuvieron en Palenque ocho años después que Waldeck-, y constata la rápida destrucción de los monumentos. No pierde la ocasión para despotricar contra Del Río, a quien acusa de haber iniciado el proceso de deterioro, sin haber sido capaz de dejar registro del estado virginal en el que encontró las ruinas. Tampoco Dupaix, quien, "acompañado de Castañeda como dibujante, no hizo nada bien hecho, porque Castañeda no sabe dibujar". Y recuerda haber comparado sus ilustraciones con las de Catherwood, quien aprehendió bien las siluetas de los monumentos, "ya que fueron hechos con la cámara lúcida", pero le parecen demasiado pequeños y faltos del detalle necesario para el estudio de los anticuarios. Así, por fin, escribe:

Él pasó un mes en las ruinas. Yo, que viví y trabajé ahí activamente cerca de tres años [!], probablemente jamás seré publicado por la razón de que mi obra es demasiado colosal para un editor [...] cuando mis trabajos caigan en las manos de jueces competentes, la posteridad me rendirá la justicia de decir que, de todos los viajeros que estuvieron en las ruinas, yo fui el único que las describió, comentó y dibujó con precisión. ${ }^{27}$

Waldeck creía firmemente que sus dibujos ofrecían fieles registros de los monumentos hasta en sus más mínimos

27 NL-Ayer, Waldeck Drawings, ms. anexo a los dibujos, f. 174. 
detalles. En Palenque no utilizó ni la cámara lúcida ni la cámara oscura. Fue sólo en Campeche que adquirió una, y, según anota en el diario, le sería particularmente útil para trabajar a mayor velocidad, "porque puedo hacer un dibujo en 1 hora, que de otro modo serían 4 ". ${ }^{28}$ Como auxilio técnico para realizar las primeras versiones de los monumentos, en Palenque solía dibujar un reticulado de fondo en las hojas, lo que probablemente le haya servido como sistema de referencia para no errar en las proporciones, sobre todo en objetos de más difícil acceso y donde no era posible una observación frontal.

Entre los trabajos más minuciosos, llama la atención una bella hoja a la acuarela, con representaciones de cuatro diferentes frisos decorativos que el artista viajero dice haber identificado a partir de fragmentos dispersos en el palacio y por la huella que habrían dejado en las paredes. No obstante, hoy es posible afirmar que, en la forma representada por Waldeck, estos filetes de $5.5 \mathrm{~cm}$ a $10.5 \mathrm{~cm}$ de ancho, no corresponden al repertorio de formas de la escultura maya en Palenque. Su modelado sigue la tradición de arquetipos clásicos; repiten el diseño de las molduras de zarcillos o acantos, con una configuración rítmica en la que aparecen motivos zoomórficos o antropomórficos. Para adecuar ese elemento decorativo al mundo palencano, el pintor viajero los adapta a las circunstancias, de modo que el entrelazado de vegetales que organizan el espacio en este caso está compuesto por las hojas de "una planta parásita muy común en los bosques de Palenque", y entre las figuras se intercalan motivos que parecen cabezas de elefantes,

${ }^{28}$ BL, ms. Add 41684, f. 183 (anotación del 28 de julio de 1834). 
perfiles de cabezas humanas y objetos con forma de huevo con un decorado de dibujos geométricos. Se trata, de hecho, más que de hallazgos, de construcciones hipotéticas hechas a partir de fragmentos que el artista interpreta de manera bastante libre. En el dorso de la hoja Waldeck comenta estos decorados y, en cada caso, elabora complejas explicaciones del contenido simbólico que estos decorados habrían tenido. ${ }^{29}$

Figura 1
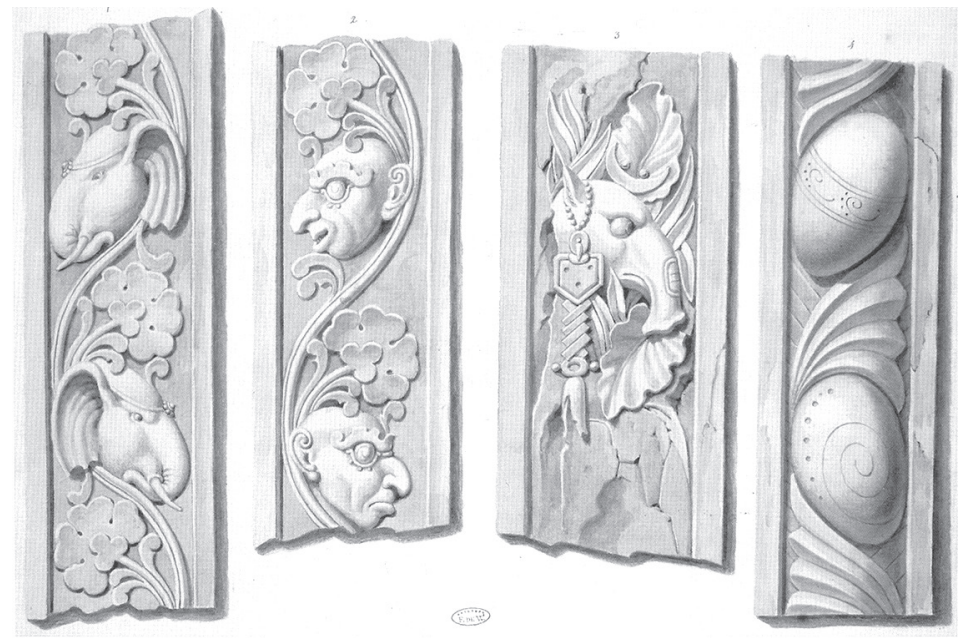

Jean-Frédéric Waldeck

Frisos ornamentales - Palacio, Palenque

Acuarela sobre papel, $28 \times 36.5 \mathrm{~cm}$

Newberry Library, Ayer Collection, f. 249.

${ }^{29}$ NL-Ayer, Waldeck Drawings, dibujo f. 249; anotaciones en el dorso de la acuarela. 
Esa forma de abordar los restos arqueológicos es muy frecuente, sobre todo cuando se trata de relieves cuyo estado de conservación era, ya entonces, muy fragmentario. El procedimiento de un registro que al mismo tiempo implica una contundente restauración es aplicado de forma explícita y con férrea convicción. "No resta más que la silueta de la figura”, escribe sobre la hoja en que dibuja el asíllamado Hermoso Relieve del Templo del Jaguar. No obstante, tiene la certeza de que "se puede restaurar este bello monumento sin dudas con base en lo que resta". ${ }^{30}$

Esta pieza le resultaría tanto más seductora, porque ya en Londres había tenido en sus manos la versión que de ella había dibujado Armendáriz cuando trabajó a las órdenes de Del Río, es decir, uno de los dibujos que habían despertado su curiosidad por el mundo prehispánico. Su dibujo es, sin duda, incomparablemente más elaborado que el de su antecesor en esa tarea, a pesar de que, a medio siglo de distancia, él se encontraba en clara desventaja debido al significativo deterioro que había sufrido la obra. Califica la pieza de "tan bella como los más perfectos monumentos romanos", ${ }^{31}$ y cuando ejecuta la versión al óleo, para dar más énfasis a su valoración, en el dorso de la pintura copia un pasaje de la narrativa de John Stephens, que vio la obra en un estado de deterioro aún mayor; el trecho citado del viajero estadounidense dice que, "por su ejecución [esa obra es] superior a todos los relieves en estuco que se encuentran en Palenque". ${ }^{32}$

30 BNF-Estampes, Cod. Gd 50c-e, f. M238988; anotaciones en el dibujo.

31 BNF-Estampes, Cod. Gd 50c-e, f. M238988; anotaciones en el dibujo.

32 BNF-Estampes, Cod. Gd 50c-e, f. M238854; anotaciones en el dorso de la pintura. 
Figura 2

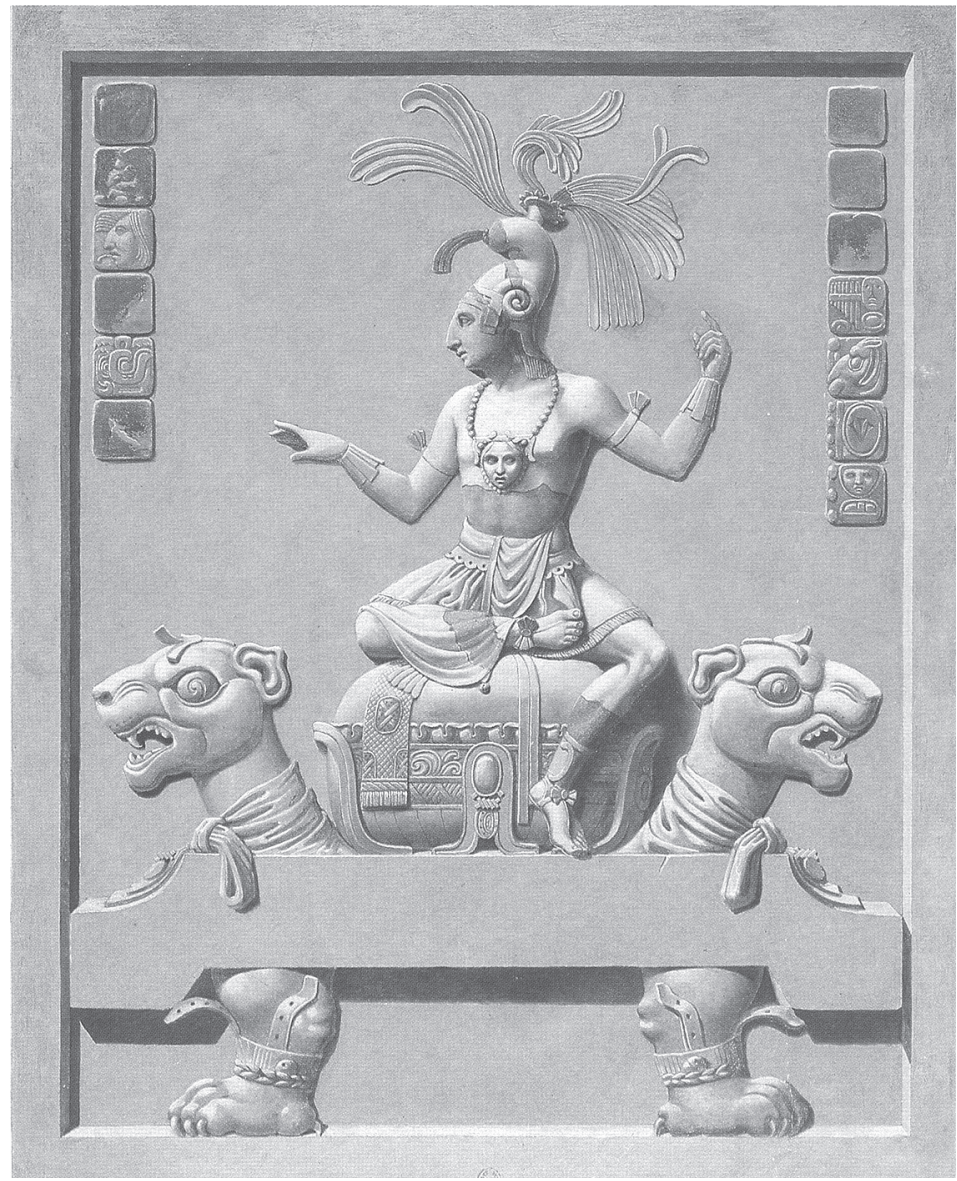

Jean-Frédéric Waldeck

Hermoso Relieve-Templo del Jaguar, Palenque

Óleo sobre cartón, $55 \times 41.8 \mathrm{~cm}$

Bibliothèque Nationale de France, Cabinet des Estampes, f. M238854. 
Waldeck asume que ha intervenido la figura, restaurándola. En efecto, en la versión pintada destaca en color verde las partes que reconoce haber completado, las cuales, en verdad, son bien pocas. Esto es sintomático de su forma de ver, ya que, a pesar de la advertencia sobre el mal estado de conservación de la figura, de la que dice que no resta más que la silueta, él sólo asume como restauración una parte del tronco, el rostro y una franja vertical que va del cuello hasta el gorro. Vale decir, atribuye total legitimidad al resto de la figura, aunque no exista. En ese sentido, por ejemplo, es enfático al decir que "el gorro frigio está bien trazado"33 y, posteriormente, en la versión al óleo, lo interpreta como el "signo del antiguo Culhuacan", ${ }^{34}$ creando una relación entre el tocado de esa figura maya y el glifo náhuatl para el lugar de Colhuacan. Como esta asociación, en fin, son numerosos los puentes que el artista construye para componer su figura y al mismo tiempo darle un sentido, justificar su aspecto, como él dice, "sin dudas con base en lo que resta".

Con la persistente intención de llamar la atención sobre su trabajo, que - según afirma - siempre realizado de primera mano, elaborando representaciones cuidadosas y fieles, Waldeck fue incisivo en sus comentarios sobre otro relieve en estuco que dibujó, pintó y grabó, procedente del edificio A del Palacio, esta vez, una obra bastante mejor conservada que el monumento anterior. Como en el caso del Hermoso Relieve, esta escena, que muestra tres figuras, una de pie y dos sentadas a sus pies, fue dibujada por Armendáriz

33 BNF-Estampes, Cod. Gd 50c-e, f. M238988; anotaciones en el dibujo. ${ }^{34}$ BNF-Estampes, Cod. Gd 50c-e, f. M238854; anotaciones en el dorso de la pintura. 
y en 1822 grabada por Waldeck. El dibujo circuló en diversas copias ya antes de su publicación en la obra inglesa de Del Río, una de las cuales llegó a manos de Alexander von Humboldt, que la publicó en su Vistas de las cordilleras y monumentos de los pueblos indígenas de América (1810) con el equívoco título de "Relieve mexicano encontrado en Oaxaca [dibujo proporcionado por el Sr. Cervantes y grabado por F. Pinelli en Roma]". ${ }^{35}$ El desliz de Humboldt, causado por no haber recibido la información correspondiente a la procedencia palencana de la pieza, fue cobrado una y otra vez por Waldeck, que entre sus observaciones escribió: "Me esmero por no hablar sino de aquello que he visto, así, puedo asegurar que ninguna de mis descripciones - tan mal escritas como puedan estar - carece de fidelidad, que es la primera exigencia que cabe hacer a un viaje". ${ }^{36}$

Con independencia de la identificación errada de la imagen que hizo Humboldt, su interpretación de esa obra pone en evidencia que los vuelos de interpretación de un continente a otro no constituían una construcción intelectual singular de Waldeck. En ese sentido, en su libro, al concluir el comentario de la imagen, el americanista prusiano escribe:

Los esclavos, sentados y con las piernas cruzadas, representados a los pies del vencedor, son en extremo notables por su postura y desnudez. El que está colocado a la izquierda se asemeja a la figura de esos santos que se ven frecuentemente en los cuadros hindúes y que el navegante Roblet ha encontrado sobre la

35 Para un estudio sobre las copias de los dibujos de Armendáriz y su circulación, consúltese García Sárz, "Antonio del Río y Guillermo Dupaix", pp. 99-119.

36 NL-Ayer, ms. 1263, f. 19. 
costa noroeste de América, entre las pinturas jeroglíficas de los nativos del canal de Cox. Sería fácil reconocer en este relieve el gorro frigio y el delantal de las estatuas egipcias, si se desearan seguir las huellas de un sabio que, llevado de una imaginación ardiente, ha creído encontrar en el nuevo continente inscripciones cartaginesas y monumentos fenicios. ${ }^{37}$

Es cierto que Humboldt pone cierta distancia respecto a una interpretación más especulativa de las figuras. Pero es él quien constata la semejanza de una de las figuras del relieve maya con motivos de origen indio, y a partir de ahí cita a otros autores que contribuyen a dar plausibilidad a esa observación. Como mostró Lubrich, para Humboldt “Oriente sirve de modelo a la percepción de América” y en sus figuras de lenguaje hay una fuerte carga que orientaliza a este continente. ${ }^{38}$ La percepción de la realidad extraeuropea, en particular de lo que se llamaba Nuevo Mundo, es abordada con una lente teñida de tonos orientalistas. Esto se legitima en el horizonte cultural de Occidente desde finales de la Ilustración. Sea en estudios lingüísticos o en la aproximación a las tradiciones religiosas, el recurso a Oriente - entendido en un sentido amplio-, procurando raíces y explicaciones, es constante.

Waldeck, por su parte, exacerbó esas búsquedas, que con frecuencia lo llevaron a tejer vínculos genealógicos, unas veces con la historia de las tribus de Israel, otras con la tradición de la India. ${ }^{39}$ Pero el campo principal de sus

37 Humboldt, Vistas de las cordilleras, p. 70.

38 Lubrich, "Egipcios por doquier", p. 9.

39 Carolina Depetris ha estudiado el contexto histórico cultural de las diversas formas de orientalismo que identifica en Waldeck; consúltese 
preocupaciones se sitúa en el ámbito de las formas y ahí actúa, sin duda, con una desenvoltura que, en una mirada retrospectiva, puede parecer hasta desenfadada.

Este asunto fue objeto de largas y en parte también engorrosas "Reflexiones" en el manuscrito donde comenta algunos de los más destacados monumentos de las ruinas de Palenque. La gestación de esas obras de la arquitectura y la plástica maya obedece a un mecanismo universal, que llama de recordatio o reminiscencia. Según su comprensión, existe en los pueblos, específicamente en la nación maya, la memoria ancestral, donde quedaron grabadas las justas ideas de las bellas proporciones y de un estilo puro. Se conserva, pues, un conocimiento de las obras maestras de la humanidad. Según Waldeck, ese saber se ha difundido por caminos que desconocemos, pero su presencia se percibe por vía intuitiva, en particular en el ámbito de la creación, donde las primeras impresiones del estilo bello siempre se manifestarán. "Es eso lo que me dicen los monumentos de Ototium”, escribe refiriéndose a las obras de Palenque, que llama Ototium;

[...] es también lo que dirán a todos los artistas que verán después de mí. El conocedor que examina un cuadro reconoce enseguida la escuela que lo ha producido, pero la pincelada, la factura, son sutilezas del oficio que sólo raramente pueden ser reconocidas como verdaderas o falsas por otro que no sea

de esta autora: Depetris, “Influencia del orientalismo", pp. 227-246; “El orientalismo como episteme”, pp. 10-23, y "El relato del viaje moderno", pp. 109-126. Para las relaciones que Waldeck tejió entre el México prehispánico y la Antigüedad clásica, véase también Diener, "El viajero Jean-Frédéric Waldeck", pp. 79-87. 
el que es capaz de copiar con perfección lo que tiene ante sus ojos $[\ldots]^{40}$

Dos principios orientan el trabajo de Waldeck, en la expectativa de contribuir en la construcción de conocimiento por medio de las investigaciones arqueológicas. En primer lugar, considera que el trabajo de campo es esencial porque permite el indispensable contacto de primera mano, que él siempre defendió, y debe ser abordado con rigor, cuidando de mapear lo que existe y registrar cuidadosamente las medidas de los objetos, cuestiones que, por lo demás, él realizó con máximo cuidado. En segundo lugar, destaca la importancia de la copia de los monumentos, tarea en la que la sensibilidad del artista desempeña un papel relevante. La copia permite, según su análisis, una compenetración profunda con obras que, precisamente por ser creaciones artísticas, en el proceso de registro visual él aprehende de manera integral.

La mirada que Waldeck lanza sobre las ruinas lleva la carga de un saber enciclopédico. Ver es para él una actividad que se desarrolla simultáneamente al hecho de establecer asociaciones con motivos de un horizonte cultural universal. Ya desde su llegada a México traduce todo lo que ve a un lenguaje erudito de amplitud planetaria. En Tampico le llama la atención la belleza de las muchachas del pueblo que van a buscar agua a la fuente y en las que descubre una analogía con las egipcias, y los vasos en los que cargan el agua le parecen perfectamente etruscos. En términos parecidos comenta el paisaje que recorre entre el puerto y su destino

40 NL-Ayer, ms. 1263, f. 11. 
en el pueblo minero de Tlalpujahua. Después de un trecho penoso por una cañada pedregosa, llega a un espacio que lo hace sentirse en Calabria; la silueta de las montañas, los bosques de pinos y el tono rojo de la tierra, a su entender, evocan Italia; "los propios habitantes dan a estas montañas un aire italiano". ${ }^{41}$

Esta forma de apropiarse de las figuras o del paisaje, traduciéndolos a su lenguaje, es también la modalidad en que se aproxima a los monumentos arqueológicos. Es con esa lógica que inicia su comentario sobre el Relieve Oval de la casa E del Palacio de Palenque, que califica de "quizá lo más interesante de las ruinas", anotando: "Sobre un sofá o trono está sentada de forma asiática una mujer que parece recibir una ofrenda". Enseguida identifica la figura colocada enfrente, que lleva la ofrenda, como "un [personaje] arrodillado que le ofrece un tocado compuesto de grandes perlas y coronado con plumas - esta figura tiene trazos etiópicos". ${ }^{42}$

El relieve, como sabemos hoy, es una conmemoración de la entronización del rey Pakal, que aparece representado sentado en el trono de un jaguar bicéfalo, en el momento de recibir de su madre la insignia del poder en forma de tocado real. La cuestión relevante aquí no es el hecho de que Waldeck desconozca detalles históricos entonces insospechados y que construya una interpretación de acuerdo con las posibilidades de la época. Interesa, sí, cómo Waldeck crea su representación. En lo sustancial, el dibujo a tinta, vale decir, la primera versión de su registro, ya representa

41 NL-Ayer, ms. 1261, núm. 1, f. 27 (anotación del 12 de mayo de 1825) y ff. 42-43 (anotación del 26 de mayo de 1825.

42 NL-Ayer, ms. 1263, f. 17. 
todos los elementos que el artista enuncia en su descripción: las dos figuras llevan el adorno nasal que en el texto es identificado como el nesem de la tradición judaica; el tocado de la figura sentada en el trono incluye, entre otros atributos, un delfín y una mano de la que pende un cordón con una borla. Pero, sobre todo, el modelado de los cuerpos, cuya silueta y trazos generales son bastante fieles, se adecuan a lo que el artista vio según su comprensión de la escena. La figura sentada en el trono adquiere mayor volumen y el dibujante redondea las formas, mientras que el rostro de la figura oferente aparece representado con la nariz y la boca acentuados, de una forma que no es idéntica con el relieve, pero cuya intención es la de incorporar lo que entendería como un trazo anatómico etiópico. Más aún que en el dibujo, en las dos versiones siguientes, una grisalla y una acuarela en tonos sepia, la interpretación se consolida mediante juegos de luz y sombra. ${ }^{43}$

Al concluir su descripción, Waldeck acrecienta otra connotación que abre aún más el espectro de las referencias: "Esta reina está vestida tan ligeramente que uno no percibe que lleva un pequeño calzón que le llega hasta la mitad de los muslos, si no fuera por una especie de borde dentado que lo remata". Y entonces, mediante una referencia literaria, asocia la figura a la tradición latina: "Los tejidos empleados por las mujeres, según Horacio y Séneca, eran tan finos que dejaban ver todas las partes del cuerpo como si estuviesen desnudas". ${ }^{44}$

${ }^{43}$ Para el dibujo véase NL-Ayer, Waldeck Drawings, dibujo f. 187; para la grisalla: NL-Ayer, Waldeck Drawings, dibujo f. 188; para la acuarela BNF-Estampes: Cod. Gd 50c-e, f. 238807.

${ }^{44}$ NL-Ayer, ms. 1263, f. 17. 


\section{Figura 3}

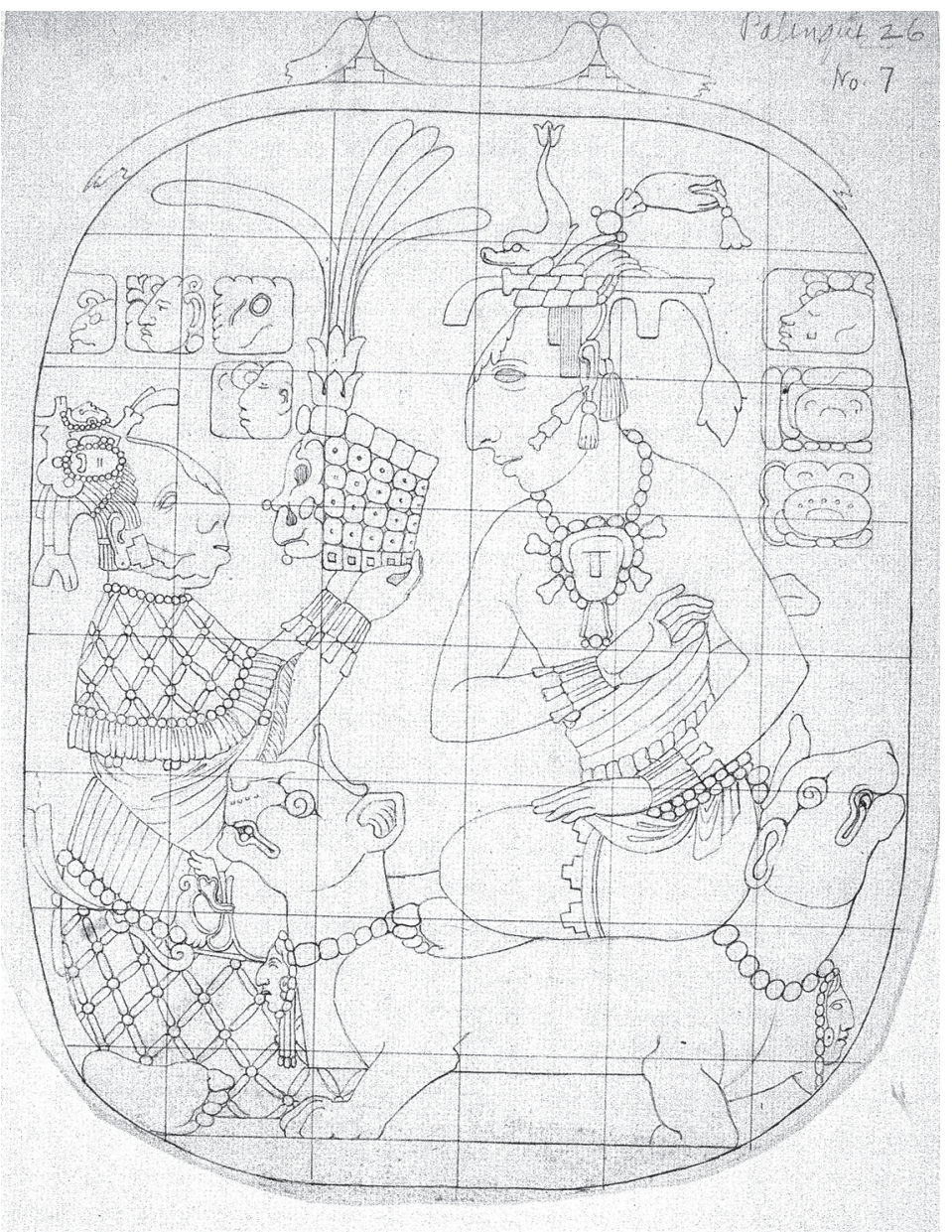

Jean-Frédéric Waldeck

Relieve oval - Palacio, Palenque

Tinta sobre papel, $35 \times 23.5 \mathrm{~cm}$

Newberry Library, Ayer Collection, f. 187. 
Waldeck formuló apenas una somera interpretación del conjunto del relieve, pero sí se detuvo en la descripción de las partes, es decir, en algunos de los atributos. Intuyó que se trataba de una pieza destacada y le atribuyó un alto valor estético. Las evocaciones más diversas que le sugirió ese relieve, desde las referencias asiáticas de la postura de la figura principal y el tipo humano etiópico de la otra, pasando por la presencia de lo que interpreta como un motivo de tradición judía, hasta la alusión a un comportamiento inspirado en el mundo clásico romano en cuanto a la vestimenta, son trazos que componen un cuadro amplio del repertorio de herramientas culturales con las que el viajero operaba.

Ese enmarañado conjunto de remisiones formulado en lenguaje visual y explicitado en palabras, en sí mismo, no fue motivo de críticas ni parece haber desconcertado a los contemporáneos del pintor. En la introducción al libro sobre Palenque, donde se publicó una selección de los dibujos de Waldeck, el autor del texto, Charles Étienne Brasseur de Bourbourg, opina, en un contexto amplio, que se trata de correspondencias a las que "nuestros estudios nos conducen de forma absolutamente natural”; incluso elogia la construcción de ese tipo de analogías, y retóricamente pregunta: “ ¿no son acaso esas comparaciones las que están destinadas a lanzar más luz sobre los orígenes de las razas y de las naciones?". ${ }^{45}$

Pero lo que sí se objetó en la obra de Waldeck fue su tendencia a ir más allá de lo que su oficio de explorador le permitía. El informe de la comisión que evaluó esa obra en 1860

45 Waldeck y Brasseur de Bourbourg, Recherches sur les Ruines de Palenqué, p. xvii. 
por orden del gobierno francés, para decidir sobre su adquisición, llama explícitamente la atención sobre la separación de las funciones; la tarea del explorador era reunir materiales que el hombre de ciencia interpretará posteriormente. El autor material del informe, Leonce Angrand (1808-1886), diplomático y él mismo un explorador $-\mathrm{y}$ buen dibujante- que había visitado las ruinas del altiplano andino, era un conocedor de la problemática propia del registro y estudio de los monumentos arqueológicos. En sus opiniones, ciertamente asumidas por la comisión, Angrand ve la necesidad de establecer límites a las tareas del viajero, en cuanto explorador y en cuanto artista. ${ }^{46}$ En ese sentido, unas veces elogia la minuciosidad del registro que constata en los dibujos palencanos de Waldeck, otras, critica el espíritu artístico que lo "induce a trazar sobre el papel más de lo que realmente ve". He ahí un conflicto insalvable, ya que la opinión del evaluador se contrapone absolutamente con la comprensión que Waldeck tenía de su tarea como artista viajero y explorador. Para Angrand, "las restauraciones están íntimamente relacionadas con el conocimiento del genio, de las costumbres y de la historia de las nacionalidades extinguidas, de modo que no pueden ser ejecutadas sólo con el auxilio de las artes del dibujo". ${ }^{47}$ Para Waldeck, en cambio, como vimos antes, en el proceso de copiar el dibujante se compenetra con su objeto como nadie podría hacerlo mejor, lo que

\footnotetext{
${ }^{46}$ Para un análisis sobre el informe de Angrand, consúltese García Sárz, "Antonio del Río y Guillermo Dupaix".

47 Véase el informe de Leonce Angrand, de 1860, publicado en Brasseur De Bourbourg, Recherches sur les Ruines de Palenqué, pp. vii-xi; la cita corresponde a la p. viii. Para una defensa de la autoridad intelectual de Waldeck véase TAYAC, "La Comission du Mexique. M. de Waldeck".
} 
le proporciona una comprensión profunda de los fenómenos históricos.

Consciente de estas contradicciones y con la intención de zanjar de antemano futuros conflictos, Angrand, y con él la comisión evaluadora, recomendó la compra de la obra como un paso previo y requisito indispensable para la publicación de los dibujos.

Waldeck no calzaba en el molde establecido por las instituciones. En la comprensión que él tenía de su trabajo, el papel que le cabía desempeñar no tenía límites y entre sus herramientas, la intuición artística era primordial. De acuerdo con esas expectativas, no acotó el ámbito de sus intereses y curiosidad, y, por lo general, asumió que las incursiones en los más diversos campos del saber no eran meras actividades marginales, sino que contribuían a dar sustento a su quehacer artístico y podrían llegar a ofrecer aportaciones sustantivas para las ciencias. Y, de hecho, en ocasiones así fueron reconocidas.

Ese es el caso, por ejemplo, de sus estudios de las lenguas del México antiguo, que venía cultivando desde los años que había pasado en la capital. Y, según anota en su diario, en Palenque dedicó largas jornadas a elaborar tablas comparativas de "palabras en tres lenguas: mexicano, maya y chol”, y se empeña por aprehender la lengua viva, para lo que procura informantes que le muestren la pronunciación de las palabras en maya y en chol. ${ }^{48}$ Una parte de esos registros llamó la atención del lingüista y estudioso del náhuatl Eduard Buschmann (1805-1880) - que había sido el colaborador más próximo de Wilhelm von Humboldt (1767-1835),

${ }^{48}$ BL, ms. Add 41684, f. 119 (anotación del 12/11/1832). 
el hermano mayor de Alexander y uno de los más famosos lingüistas de la época y estudioso de las lenguas americanas -, y a finales de la década de 1850, en un gesto que pone en evidencia la estimación que ese trabajo le merecía, Buschmann hizo llegar una copia de las anotaciones lingüísticas de Waldeck al brasilianista bávaro C. F. Ph. von Martius, cuando este último preparaba una obra de clasificación de las lenguas americanas, con especial atención a las lenguas habladas en Brasil. ${ }^{49}$

En los estudios de lingüística, una de las máximas aspiraciones de Waldeck era descifrar las inscripciones de los monumentos mayas. Con ese objetivo, copió numerosas inscripciones de Palenque y, como parte de estos trabajos, en el diario menciona que, cuando reprodujo el Relieve de la Cruz, dedicó particular atención a preparar los cuadrados de los glifos y a dibujar uno a uno su contenido. Consta, por lo demás, que ese afán lo llevó a desarrollar una gran admiración por el egiptólogo francés que descifró la escritura jeroglífica, Jean-François Champollion (1790-1832), cuya muerte registra en su diario. Cuando retomó sus trabajos, en la década de 1860, Waldeck publicó un artículo sobre el Relieve de la Cruz que, en lo sustancial, es una tentativa de sintetizar sus investigaciones sobre la escritura maya. Con bastante cautela expone que se trata de un sistema gráfico compuesto de dos tipos de elementos: por una parte, la representación de una serie de objetos, por otra, "los apéndices laterales que, en forma de barras verticales y puntos resaltados con volumen, parecen destinados a modificar

49 Para la correspondencia entre Buschmann y Martius, véase BSB-HA, acervo Martiusiana, II, A, 2 Buschmann, Eduard. 
el significado de los objetos [representados]". ${ }^{50}$ Sobre estos signos, que parece interpretar como elementos morfológicos del lenguaje, declara no ser capaz de decir nada. En seguida, a partir de los motivos representados, organiza en una tipología de diez categorías temáticas los 195 glifos que había registrado del Relieve de la Cruz. Al concluir su escrito admite que no ha conseguido sino formular dudas, pero que no posee respuesta para ninguna de ellas. “¿A qué sistema pertenece esa escritura?, ¿ es simbólica o fonética?, ¿ es la versión gráfica de alguna de las lenguas que se ha perpetuado por siglos en ese suelo y que aún está en uso [...]?”. Por fin, retoma un procedimiento de argumentación que le es habitual: "La prodigiosa multiplicidad de los signos chinos [...] reaparece aquí: de los dos mil glifos que he estudiado y dibujado en Palenque, no he encontrado más de diez que presenten parejas análogas [...] quizá un estudio profundo de los antiguos caracteres chinos contribuiría a encontrar el camino para la interpretación de estos misteriosos jeroglíficos". ${ }^{51}$

$\mathrm{Al}$ mismo tiempo que procuraba reunir materiales sobre las lenguas, Waldeck también incursionó en el campo de la antropología física. Fue el hallazgo de un cráneo durante las excavaciones en la torre del palacio lo que lo llevó a sistematizar algunas ideas. Primero elaboró un cuadro comparativo con la representación de diversos perfiles, organizados - a lo que parece - siguiendo el modelo tipológico elaborado por el naturalista e ilustrador holandés Petrus Camper

50 WALDECK, "Description du bas-relief de la Croix"; la cita es de la p. 77.

51 Waldeck, "Description du bas-relief de la Croix", p. 86. 
(1722-1789). ${ }^{52}$ Después, en diciembre de 1832, resumió sus investigaciones en un texto ilustrado que lleva el título de “Consideraciones sobre la amplitud del ángulo facial de los habitantes de Palenque y su relación con los pueblos de Asia”. ${ }^{53}$ Así, por vía del estudio de los ángulos craneanos, afirmaba haber descubierto un argumento incontestable de que los palencanos estarían vinculados con la raza asiática. Esas especulaciones podrían ser de su propia invención o quizá estén asociados a las investigaciones sobre craneología de Johann Friedrich Blumenbach (1752-1840), el médico y profesor de Anatomía y Antropología Física de la Universidad de Gotinga, cuyas ideas contribuyeron decisivamente a modelar el mundo referencial científico de los viajeros desde finales del siglo xVIII e inicios del xix, entre ellos de Alexander von Humboldt.

Con base en estas y otras incursiones en diversos ámbitos del saber, Waldeck se proponía explorar la identidad histórica del pueblo que había creado el complejo arquitectónico y artístico de Palenque. Él admite, como Angrand, que una comprensión profunda del legado de esa nación exige el conocimiento de su genio, de sus costumbres y de su historia. En ese sentido, al concluir el artículo sobre el Relieve de la Cruz parece incluso querer responder a este juez de su obra, reafirmando la necesidad de una compenetración con los aspectos esenciales de la vida de ese pueblo, los cuales, en su opinión, se materializan en primer lugar en su sensibilidad estética. "La nación que ha construido esos edificios", escribe en tono conclusivo y aparentemente dando pie atrás

52 NL-Ayer, Waldeck Drawings, dibujo f. 227.

53 NL-Ayer, ms. 1265, ff. 81-83. 
en sus afirmaciones del entrelazamiento de los más diversos pueblos del planeta, "es a mi entender una nación autóctona, dotada con una inteligencia artística superior y que se ha conducido a sí misma en la adquisición de lo bello, siguiendo una gradación que es posible acompañar [...]" ${ }^{54}$

El camino de perfección a que alude se inicia con "los Colosos del Palacio”. Se refiere a las figuras de grandes dimensiones representadas en las estelas inclinadas que rodean el patio noreste del palacio. Más que en cualquiera de los registros de las representaciones plásticas de Palenque, al ilustrar esas estelas Waldeck recurrió a un lenguaje con una fuerte carga expresiva. Se verifican aquí, de la misma forma que en sus demás dibujos, alteraciones más o menos sutiles, que unas veces afectan a la constitución física de los personajes, otras, a sus aderezos, de acuerdo con la comprensión que el pintor construía de cada figura, sea atribuyéndole un carácter esencialmente palencano - como define a la primera figura del grupo de cuatro, a la izquierda de las escaleras-, sea identificando trazos de tradición babilónica o egipcia, como describe las dos figuras situadas a continuación, en el mismo conjunto. El dibujo inicial representa las figuras en un primer plano inmediato al observador. En un segundo momento, en una versión a lápiz y grisalla, destacó los aspectos plásticos de los personajes. Finalmente elaboró una escena - divulgada en una litografía coloreada - con el grupo de las cuatro figuras, colocando en primer plano, directamente delante de las estelas, un desnudo femenino que da una medida humana al conjunto. ${ }^{55}$

54 Waldeck, “Description du bas-relief de la Croix”, p. 87.

55 Para el dibujo véase NL-Ayer, Waldeck Drawings, dibujo f. 186; para 
Crea así una composición en la que destaca el carácter monumental de los colosos, aumentando su tamaño, para acentuar el contraste con el cuerpo de la mujer y otorgar dimensiones sobrehumanas al conjunto escultórico. Como observó Pastory, ${ }^{56}$ Waldeck recurrió aquí a sus habilidades teatrales y llevó las figuras a una especie de escenario, con el propósito de explicar el sentido de esas esculturas en el complejo de las ruinas de Palenque.

\section{Figura 4}

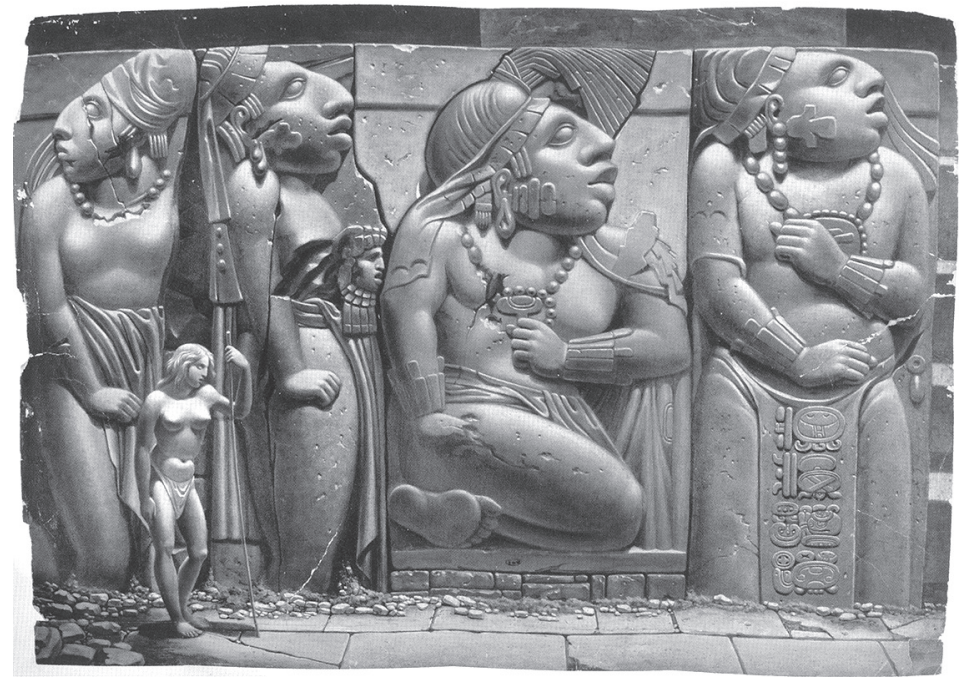

Jean-Frédéric Waldeck

Los Colosos - Palacio, Palenque

Litografía coloreada, $36 \times 55.3 \mathrm{~cm}$

Newberry Library, Ayer Collection, f. 322.

la versión a lápiz y acuarela BNF-Estampes, Cod. Gd 50c-e, f. M238797, y para la litografía coloreada: NL-Ayer, Waldeck Drawings, dibujo f. 322. 56 Pasztory, Jean-Frédéric Waldeck, p. 41. 
En efecto, Waldeck quiso ver "proporciones heroicas” en esas figuras y las interpretó como testimonio de una tradición arcaica de la antigua ciudad maya. ${ }^{57}$ Para expresar visualmente esa importante idea de su comprensión del desarrollo estético de ese pueblo, manipuló las figuras, aproximándolas a la noción de lo sublime.

A partir de esa forma de belleza, a la que atribuye un carácter primigenio, el artista viajero supone un desenvolvimiento en el cual el Relieve de la Cruz representa el segundo escalón de un proceso que culminaría con obras de una belleza perfecta, como la pieza en estuco conocida como el Hermoso Relieve, del Templo del Jaguar.

"Sea cual fuere la originalidad que yo atribuya a la glíptica palencana”, escribe Waldeck al concluir la formulación de su hipótesis sobre la gestación y desarrollo del legado de arquitectura y escultura de Palenque, ahora sí retomando la idea de los cruces de pueblos a través de los continentes, "no puedo negar que pueblos extranjeros hayan podido venir a estos parajes, fundiéndose con la nación que ocupaba estos territorios y modificando sus procedimientos de creación artística en una medida más o menos apreciable". ${ }^{58}$

PALENQUE A TRAVÉS DE LA POÉTICA DEL ARTISTA VIAJERO

La propuesta de explicar el desarrollo histórico cultural del México prehispánico, específicamente de Palenque, recurriendo a movimientos migratorios de los pueblos de ultramar, de Europa, del África mediterránea o de Asia,

57 NL-Ayer, ms. 1263, f. 10.

58 Waldeck, "Description du bas-relief de la Croix", p. 87. 
representaba un lugar común desde finales de la Ilustración y continuó vigente hasta bien entrado el siglo xIx. El tiempo de vigencia de esta idea coincide con los años en que transcurre la larga vida de Jean-Frédéric Waldeck. No sorprende, pues, que también él haya asumido esa comprensión del devenir americano, un asunto en el que, por lo demás, no hizo ninguna contribución relevante. De hecho, a pesar de su pesada retórica, haríamos bien en no esperar de él nuevos datos o nuevas ideas en el campo del conocimiento de la historia. Waldeck no era un historiador, ni tampoco un arqueólogo. Es difícil encontrar una categoría que defina su compleja personalidad y las numerosas actividades que desempeñó. Pero para México, sin duda, fue un artista viajero. Desde esa perspectiva podremos rescatar su obra, lo que, por un lado, redundará en beneficio de una mejor - y más benevolente - evaluación histórica de ese singular personaje y, por otro, nos enriquecerá con un legado artístico - ¡no de documentación arqueológica! - que posee cualidades nada desdeñables. ${ }^{59}$

Los dibujos, las pinturas y los grabados de Waldeck nos colocan frente a un artista viajero extraordinario, con mucho oficio técnico, y ante un singular intérprete de la realidad que visita. Particularmente atractivo resulta constatar cómo la corriente del pensamiento difusionista guió su mano. Él dibuja creyendo que copia fielmente su objeto; sin embargo, desde la tribuna privilegiada que nos concede la distancia del tiempo, vemos de manera inequívoca cómo el mundo de las ideas interfiere en el proceso de su registro y

${ }^{59}$ Para una evaluación de conjunto de la obra y de la personalidad de Waldeck, véase BAUDEZ, Jean-Frédéric Waldeck, peintre, pp. 183-196. 
lo transforma, a pesar de la convicción del propio autor, en un proceso de invención.

Pocas veces nos vemos confrontados de forma tan explícita como en el caso de Waldeck, con los pormenores del lenguaje poético de un artista viajero. Él explora un terreno donde opera con convicción, porque interpreta el legado de la cultura material prehispánica no sólo como documentos históricos y sí, principalmente, como obras de arte. Todo su análisis del devenir histórico cultural del México antiguo se sustenta en un principio básico: él, un artista, puede aprehender el sentido de los objetos que se propone registrar, precisamente porque son obras de arte.

\section{SIGLAS Y REFERENCIAS}

AN Archives Nationales, París, Francia.

BL British Library, Londres, Reino Unido.

BNF-Estampes Bibliothèque Nationale de France, Cabinet des Estampes, París, Francia.

BSB-HA Bayerische Staatsbibliothek, Handschriften Abteilung-Múnich, Alemania.

NL-Ayer Newberry Library-Ayer Collection, Chicago, E. U.

Angrand, Leonce, “Rapport de M. L. Angrand”, en Waldeck y BrasSEUR DE BOURBOURG, 1866, pp. vii-xi.

Baudez, Claude-François, Jean-Frédéric Waldeck, peintre. Le premier explorateur des ruines mayas, París, Editions Hazan, 1993.

Cline, Howard F., “The Apocriphal Early Career of J.-F. Waldeck, Pioneer Americanist”, en Acta Americana, v (1947), pp. 278-299.

Cochelet, Adrien, "Lettre de M. Adrien Cochelet, consul-général, a M. Jomard, membre de l'Institut” (datada en México el 30 de diciembre de 1831), en Bulletin de la Société de Géographie, 17 (1832), pp. 101-108. 
Depetris, Carolina, "El orientalismo como episteme. Frédéric de Waldeck y las ruinas mayas", en HiN, Revista Internacional de Estudios Humboldtianos, xI: 21 (2010), pp. 10-23.

Depetris, Carolina, "El relato de viaje moderno: ¿postmodernidad escondida?”, en Cuadernos del CILHA, 14: 2 (2013), pp. 109-126.

Depetris, Carolina, "Influencia del orientalismo en la explicación del origen del pueblo y ruinas mayas: las tribus perdidas de Israel y el caso Waldeck", en Mexican Studies/Estudios Mexicanos, 25: 2 (2009), pp. 227-246.

Diener, Pablo, "El diario del artista viajero Jean-Frédéric Waldeck, 18251837”, en Anuario de Historia de América Latina, 47 (2010), pp. 105-125.

Diener, Pablo, "El viajero Jean-Frédéric Waldeck: un diálogo entre el México prehispánico y la Antigüedad clásica”, en Karge y Klein (coords.), 2016, pp. 79-87.

García Sáiz, María Concepción, “Antonio del Río y Guillermo Dupaix. El reconocimiento de una deuda histórica”, en Anales del Museo de América, 2 (1994), pp. 99-119.

Humboldt, Alexander von, Vistas de las cordilleras y monumentos de los pueblos indígenas de América, prólogo de Charles Minguet y Jean-Paul Duviols, introducción, traducción y notas de Jaime Labastida, México, Siglo Veintiuno editores, 1979.

Karge, Henrik y Bruno Klein (coords.), 1810-1910-2010. Independencias dependientes. Arte e identidades nacionales en América Latina, Fráncfort de Meno, Vervuert, 2016.

Lubrich, Oliver, “'Egipcios por doquier'. Alejandro de Humboldt y su visión 'orientalista' de América”, en HiN, Revista Internacional de Estudios Humboldtianos, III: 5 (2002), pp. 3-28.

Mestre Ghigliazza, Manuel, “Algo sobre el barón de Waldeck”, en WALDECK, 1996, pp. 25-41.

Pasztory, Esther, Jean-Frédéric Waldeck. Artist of Exotic Mexico, Albuquerque, University of New Mexico Press, 2010. 
Redacción del BULLETIN DE LA SOCIÉTÉ DE GÉOGRAPHIE, «Antiquités Américaines», en Bulletin de la Société de Géographie, 11 (1829), pp. 194-196.

Redacción del Bulletin de la Société de Géographie, "Prix pour la Description des Monumens de Palenque et de la Péninsule d'Yucatán", en Bulletin de la Société de Géographie, 13 (1830), pp. 186-187.

Redacción del Bulletin de la Société DE GÉOgRaphie, "Rapport sur le concours relatif à la géographie et aux antiquités de l'Amérique centrale”, en Bulletin de la Société de Géographie, $2^{\mathrm{a}}$ serie, 5 (1836), pp. 253-291.

Río, Antonio del, Description of the Ruins of an Ancient City Discovered near Palenque in the Kingdom of Guatemala, in Spanish America, Londres, Henry Berthoud, 1822.

Sмiтн, Mary Rebecca Darby, Recollections of two Distiguished Persons: La Marquise De Boissy and the Count De Waldeck, Filadelfia, J. B. Lippincott \& Co., 1878.

TaYac, Gaston de, "La Comission du Mexique. M. de Waldeck", en Actes de la Société d'Ethnographie, 4 (1864), pp. 256-260.

WaLdeck, Jean-Frédéric, "Extrait d’une lettre de Jean-Frédéric Waldeck, commissionné de l'expédition des recherches aux ruines de l'ancienne ville de Palenque, à M. Jomard" (datada en Palenque el 28 de agosto de 1832), en Bulletin de la Société de Géographie, 18 (1833), pp. 49-51.

Waldeck, Frédéric de, "Description du bas-relief de la Croix, desiné aux ruines de Palenqué en 1832", en Actes de la Société d'Ethnographie, $1^{\text {a }}$ serie, IV (1864), pp. 69-88.

Waldeck, Jean-Frédéric y Charles Étienne Brasseur de Beaubourg, Monuments anciens du Mexique, Palenque, Ocosingo et autres ruines de l'ancienne civilisation du Mexique, París, Arthus Bertrand Editor, 1866.

Waldeck, Jean-Frédéric, "Sur l'archéologie américaine", en Archives de la Société Américaine de France, $2^{\mathrm{a}}$ serie, 1 (1875), pp. 143-146. 
Waldeck, Federico de, Viaje pintoresco y arqueológico a la provincia de Yucatán, 1834 y 1836, México, Consejo Nacional para la Cultura y las Artes, 1996.

Waldeck, Jean-Frédéric, y Redacción del Bulletin de la Société DE GÉOGRAPHIE, “Antiquités Mexicaines”, en Bulletin de la Société de Géographie, 19 (1833), pp. 113-114.

Walkenaer, Charles Athanase, Barón de, Philippe de Larenaudière y Edme François JomARD, "Rapport sur le concours relatif à la géographie et aux antiquités de l'Amérique centrale", en Bulletin de la Société de Géographie, $2^{\mathrm{a}}$ serie, v (1836), pp. 253-291. 